\title{
Effect of Oxidation Time on the Properties of Cellulose Nanocrystals Prepared from Balsa and Kapok Fibers Using Ammonium Persulfate
}

\author{
Marwanto Marwanto ${ }^{1}$, Muhammad Iqbal Maulana ${ }^{1}$ (D), Fauzi Febrianto ${ }^{1, *}$, Nyoman Jaya Wistara ${ }^{1}$, \\ Siti Nikmatin ${ }^{2}$, Nanang Masruchin ${ }^{3}{ }^{\mathbb{D}}$, Lukmanul Hakim Zaini ${ }^{1} \mathbb{D}$, Seung-Hwan Lee ${ }^{4}$ and Nam-Hun Kim $^{4, *}$
}

1 Department of Forest Products, Faculty of Forestry and Environment, IPB University (Bogor Agricultural University), Bogor 16680, Indonesia; marwanto@workmail.com (M.M.); iqbal_2017@apps.ipb.ac.id (M.I.M.); nyomanwis@gmail.com (N.J.W.); lukmanhz@apps.ipb.ac.id (L.H.Z.)

2 Department of Physics, Faculty of Mathematics and Natural Sciences, IPB University (Bogor Agricultural University), Bogor 16680, Indonesia; snikmatin@yahoo.com

3 Research Center for Biomaterials, Indonesian Institute of Sciences (LIPI), Cibinong 16911, Indonesia; masruchin@biomaterial.lipi.go.id

4 Department of Forest Biomaterial Engineering, College of Forest and Environmental Sciences, Kangwon National University, Chuncheon 24341, Korea; lshyhk@kangwon.ac.kr

* Correspondence: febrianto76@yahoo.com (F.F.); kimnh@kangwon.ac.kr (N.-H.K.)

Citation: Marwanto, M.; Maulana, M.I.; Febrianto, F.; Wistara, N.J.; Nikmatin, S.; Masruchin, N.; Zaini, L.H.; Lee, S.-H.; Kim, N.-H. Effect of Oxidation Time on the Properties of Cellulose Nanocrystals Prepared from Balsa and Kapok Fibers Using Ammonium Persulfate. Polymers 2021, 13, 1894. https://doi.org/10.3390/ polym13111894

Academic Editors: Ilaria Papa and Maria Rosaria Ricciardi

Received: 30 March 2021

Accepted: 3 June 2021

Published: 7 June 2021

Publisher's Note: MDPI stays neutral with regard to jurisdictional claims in published maps and institutional affiliations.

Copyright: (c) 2021 by the authors. Licensee MDPI, Basel, Switzerland. This article is an open access article distributed under the terms and conditions of the Creative Commons Attribution (CC BY) license (https:// creativecommons.org/licenses/by/ $4.0 /)$.

\begin{abstract}
This study aimed to evaluate the effect of ammonium persulfate's (APS) oxidation time on the characteristics of the cellulose nanocrystals (CNCs) of balsa and kapok fibers after delignification pretreatment with sodium chlorite/acetic acid. This two-step method is important for increasing the zeta potential value and achieving higher thermal stability. The fibers were partially delignified using acidified sodium chlorite for four cycles, followed by APS oxidation at $60^{\circ} \mathrm{C}$ for 8,12 , and $16 \mathrm{~h}$. The isolated CNCs with a rod-like structure showed an average diameter in the range of $5.5-12.6 \mathrm{~nm}$ and an aspect ratio of 14.7-28.2. Increasing the reaction time resulted in a gradual reduction in the CNC dimensions. The higher surface charge of the balsa and kapok CNCs was observed at a longer oxidation time. The CNCs prepared from kapok had the highest colloid stability after oxidation for 16 $\mathrm{h}(-62.27 \mathrm{mV})$. The CNCs with higher crystallinity had longer oxidation times. Thermogravimetric analysis revealed that the CNCs with a higher thermal stability had longer oxidation times. All of the parameters were influenced by the oxidation time. This study indicates that APS oxidation for 8-16 h can produce CNCs from delignified balsa and kapok with satisfactory zeta potential values and thermal stabilities.
\end{abstract}

Keywords: ammonium persulfate; balsa; cellulose nanocrystal; delignification; kapok

\section{Introduction}

Indonesia has a rich biodiversity of tree species, especially hardwoods, and has developed kapok and balsa plantations for the timber industry. These plantations also produce fibrous fruits from both species as by-products. Indonesia is the biggest exporter of kapok commodities [1]. However, balsa fibers from the fruits are still unutilized. Balsa and kapok fruit fibers have potential as raw materials for cellulose-based products. Balsa and kapok fruit fibers are hollow fibers with a high cellulose and low lignin content [1]. Our previous research revealed that balsa and kapok fibers could be transformed into nanocellulose through oxidation [2].

Nanocelluloses are classified based on their morphology, such as cellulose nanofibrils and cellulose nanocrystals (CNCs) [3]. CNCs have beneficial properties such as a high elastic modulus, low thermal expansion, high aspect ratio, large specific surface area, non-abrasive nature, nontoxicity, and surface charge [4]. In general, CNCs are produced by acid hydrolysis using concentrated sulfuric acid. This method generates nanocellulose 
with high crystallinity and sulfate group-modified surfaces [5]. Moreover, CNCs obtained through hydrolysis can also be produced with varying combinations of acids [6-10], organic acids [11], and solid acids [12]. However, CNCs obtained through acid hydrolysis have a low thermal stability [5], limiting their applications because of the presence of a sulfate group on its surface [13].

Another study has been conducted to produce CNCs with a higher thermal stability, using the ammonium persulfate (APS) oxidation method. The APS oxidation method produces nanocellulose with a $-\mathrm{COOH}$ surface charge [14]. This method produces CNCs with a higher thermal stability than conventional hydrolysis with sulfuric acid $[15,16]$. However, compared to other methods (acid hydrolysis and TEMPO oxidation), the APS oxidation method produces a lower surface charge [17]. High thermal stability and high surface charge are specific characteristics of nanocellulose. They are required for expansion in many applications [5,18-23]. The surface charge of nanocellulose is described by the zeta potential and is formed during the isolation or surface modification process.

Previous research reported that the pretreatment of raw materials improved the zeta potential $[17,24]$. Moreover, the zeta potential was also affected by the oxidation time. A longer oxidation time results in a higher zeta potential [24]. Another pretreatment process used for impurity removal is delignification with sodium chlorite/acetic acid [25]. Sodium chlorite/acetic acid delignification can selectively remove lignin. It generates fibers with more roughness and porosity [26]. It is important to increase the penetration of the APS solution into the fibers.

Currently, there is no information on combining delignification with sodium chlorite/acetic acid (SC/AA) and APS oxidation methods to produce CNCs from a single fiber. This study aims to determine the effect of APS oxidation time after SC/AA delignification on the characteristics of balsa and kapok CNCs, especially their thermal stability and surface charge. This information provides a deeper understanding of the characteristics of balsa and kapok CNCs and their potential applications.

\section{Materials and Methods}

\subsection{Materials}

Kapok fibers (38.09\% $\alpha$-cellulose, $14.10 \%$ lignin, and $45.64 \%$ hemicellulose) and balsa fibers (44.62\% $\alpha$-cellulose, $16.60 \%$ lignin, and 37.35\% hemicellulose) [1] were obtained from the plant collection of IPB University, Bogor, Indonesia. The balsa and kapok fibers were removed from their pods, separated from their seeds, and dried at room temperature. The fibers were milled with a laboratory cutting mill to prepare a 40-60 mesh fiber powder. The sodium chlorite $\left(\mathrm{NaClO}_{2}\right)$ at $25 \%$ solution, acetic acid $\left(\mathrm{CH}_{3} \mathrm{COOH}\right)$, APS $\left(\left(\mathrm{NH}_{4}\right)_{2} \mathrm{~S}_{2} \mathrm{O}_{8}\right)$ at $98 \%$ purity, and sodium hydroxide $(\mathrm{NaOH})$ (purchased from Merck KGaA, Darmstadt, Germany) used were of reagent grade.

\subsection{Delignification Process}

Delignification was performed by adding the milled balsa or kapok fibers ( $3 \mathrm{~g})$ to distilled water $(300 \mathrm{~mL})$ (fiber: solution ratio of 1:100 (m:v)) and kept in a water bath at $70{ }^{\circ} \mathrm{C}$. Delignification was initiated by adding sodium chlorite $(3 \mathrm{~mL})$ and acetic acid $(0.3 \mathrm{~mL})$ to the suspension. The reaction was performed continuously for $1 \mathrm{~h}$. The same amounts of sodium chlorite and acetic acid were added every hour, and the process was repeated for four cycles. The residue was filtered and washed with distilled water several times until the $\mathrm{pH}$ became neutral. The residue was then dried in an oven at $40{ }^{\circ} \mathrm{C}$ for $48 \mathrm{~h}$.

\subsection{Isolation of CNCs by APS Oxidation}

The CNCs were prepared by APS oxidation following the procedure of Oun and Rhim [27] with modifications. A total of $2 \mathrm{~g}$ of delignified balsa or kapok fibers were added to $200 \mathrm{~mL}$ (fiber: solution ratio of 1:100 (m:v)) of 1 M APS in a $250 \mathrm{~mL}$ glass beaker. The mixtures were heated at $60{ }^{\circ} \mathrm{C}$ on a hot plate and stirred vigorously for 8,12 , or $16 \mathrm{~h}$. The suspensions were centrifuged (high-speed refrigerated centrifuge with rotor 
type NA-8 and a capacity of $50 \mathrm{~mL} / 12$ tubes Suprema21, Tomy Kogyo Co. Ltd., Tokyo, Japan) at 10,000 rpm for $10 \mathrm{~min}$ to separate the APS solution. The obtained CNCs were then transferred to distilled water. The centrifuging and transfer processes were repeated until the $\mathrm{pH}$ of the suspensions reached 4.0. Sodium hydroxide $(1 \mathrm{M})$ was added to the suspensions until the $\mathrm{pH}$ increased to approximately 7 , followed by sonication for $30 \mathrm{~min}$ at $40 \%$ amplitude. The obtained CNC suspensions were kept in a cooler at $4{ }^{\circ} \mathrm{C}$ before characterization. The isolation process of the CNCs using the APS oxidation method is shown in Figure 1.

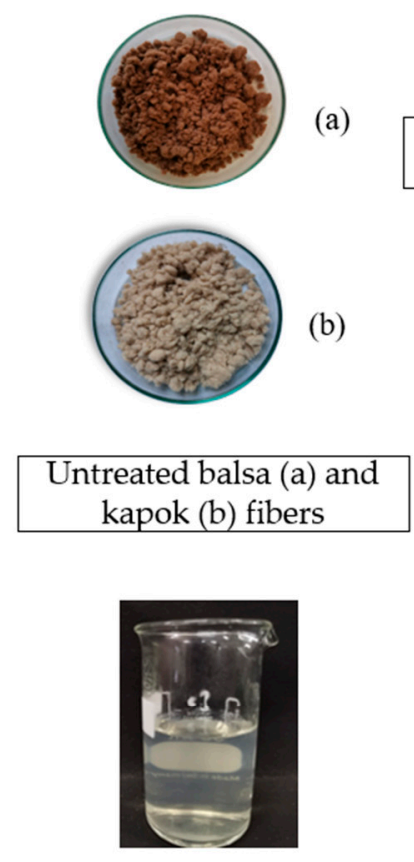

The sample was ready for characterization
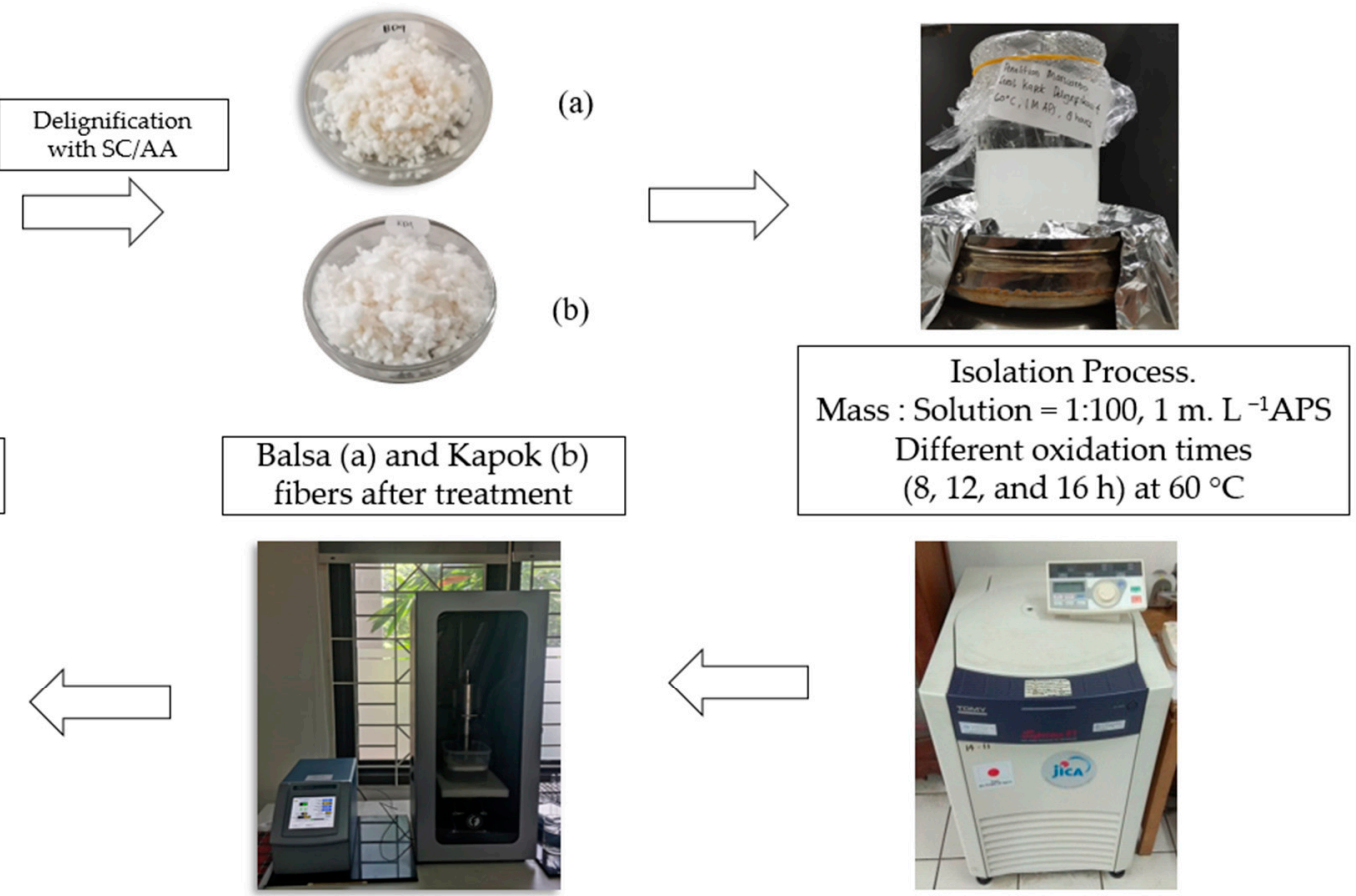

Sonication process with $40 \%$ amplitude, $30 \mathrm{~min}$

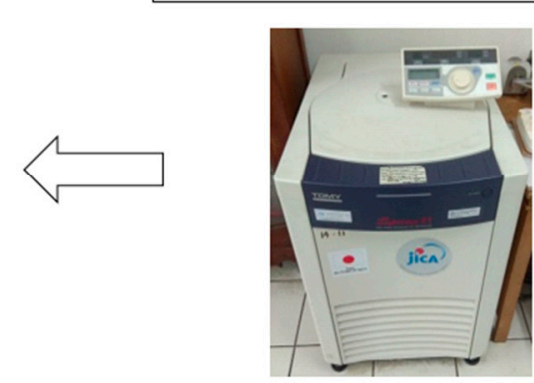

Centrifuges process for solution with 10,000 rpm, $10 \mathrm{~min}$, reached approximately $\mathrm{pH} 7$

Figure 1. Isolation process of CNCs with the APS oxidation method.

\subsection{Transmission Electron Microscopy (TEM)}

A drop of a diluted CNC suspension was dyed negatively with $0.5 \%$ aqueous uranyl acetate and placed onto a carbon-covered $\mathrm{Cu}$ framework, and then allowed to dry in a desiccator at room temperature. The size and shape of the CNCs were examined using TEM (FEI Tecnai G2 20 S-Twin, FEI, Eindhoven, The Netherlands) at $200 \mathrm{kV}$. The dimensions of the $\mathrm{CNCs}$, including length and width, were determined using ImageJ software $1.53 \mathrm{e}(\mathrm{NIH}$, Bethesda, MD, USA). Each dimension was measured using 30 replicates. The experiment had a completely randomized design with one factor, oxidation time, at three levels $(8,12$, and $16 \mathrm{~h}$ ). The data were statistically evaluated by analysis of variance (ANOVA) using IBM SPSS Statistics 25.0 (IBM Co, Armonk, NY, USA). Furthermore, Duncan's multiple range test was performed when there was a significant influence.

\subsection{Zeta Potential (ZP) Analysis}

The zeta potential of the CNCs was determined using an SZ-100 (Nanopartica series instrument, Horiba Scientific, Kyoto, Japan). Three samples were prepared from a stock suspension of $2.5 \mathrm{mg} / \mathrm{mL}$ and diluted to $0.01 \mathrm{wt} \%$ with distilled water. The zeta potential was tested in triplicates at $25^{\circ} \mathrm{C}$. 


\subsection{Functional Group Analysis}

Functional group changes in the CNCs were analyzed using Fourier transform infrared spectroscopy (FTIR-UATR Perkin Elmer Spectrum Two, PerkinElmer Inc., Waltham, MA, USA). The analysis was conducted in the wavenumber range of $4000-400 \mathrm{~cm}^{-1}$ with 16 scans at $4 \mathrm{~cm}^{-1}$ resolution and a data interval of $1 \mathrm{~cm}^{-1}$.

\subsection{Crystallinity Index (CI)}

X-ray diffraction (XRD) analyses of each sample were performed on a Shimadzu XRD-7000 MaximaX instrument (Kyoto, Japan) with CuK $\alpha$ radiation $(\lambda=0.1542 \mathrm{~nm})$ in the range of $2 \theta=10-35$, and at a speed of $4.8^{\circ} / \mathrm{min}$. The following empirical Equation (1) derived from [28] was used to calculate CI:

$$
\mathrm{CI}=\frac{I_{200}-I_{a m}}{\mathrm{I}_{200}} \times 100
$$

where $I_{200}$ is the peak intensity corresponding to the crystalline region, and $I_{a m}$ denotes the peak intensity of the amorphous fraction.

\subsection{Thermal-Stability Testing}

The thermal stability of the samples was measured using thermogravimetric analysis (TGA; STA7300 instrument, Hitachi, Tokyo, Japan). A CNC sample was heated from $27^{\circ} \mathrm{C}$ to $600{ }^{\circ} \mathrm{C}$ at a heating rate of $10{ }^{\circ} \mathrm{C} / \mathrm{min}$. Measurements were performed in a nitrogen atmosphere at a gas flow rate of $10 \mathrm{~mL} / \mathrm{min}$.

\section{Results and Discussion}

\subsection{Morphology and Particle Size Distribution of the CNCs in Suspensions}

The appearance of the CNC suspensions is shown in Figure 2. The combination of the delignification and APS oxidation methods produced CNCs in a gel form. The gel-form of the CNCs indicated that the CNCs had higher surface charges on their surfaces [29]. The appearance of the CNCs was affected by the raw materials and the oxidation time. A longer oxidation time increases the transparency of the $\mathrm{CNC}$ suspension. The appearances of the balsa and kapok CNC suspensions were slightly different. In addition, the CNCs from the kapok fibers tended to be more transparent than those from the balsa. The high transparency of the CNCs was affected by the low wavelength CNCs of kapok [30].
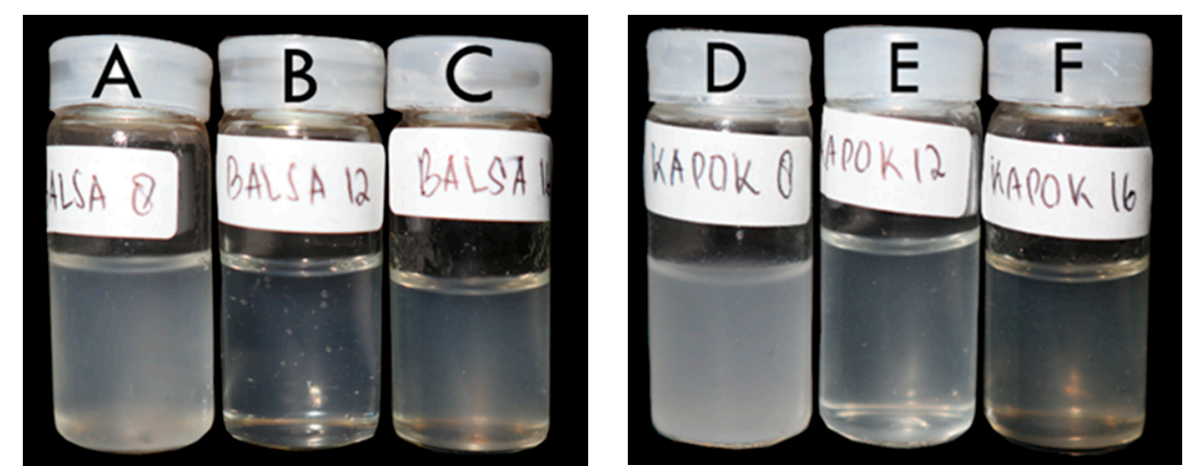

Figure 2. Appearance of CNC suspensions after oxidation using the APS method with different oxidation times. (A) Balsa, $8 \mathrm{~h}$ oxidation; (B) balsa, $12 \mathrm{~h}$ oxidation; (C) balsa, $16 \mathrm{~h}$ oxidation; (D) kapok, 8 h oxidation; (E) kapok, 12 h oxidation, and (F) kapok, 16 h oxidation.

The balsa and kapok CNCs show rod-like shapes (Figure 3). This confirms that the two-stage process performed with the APS oxidation method results in the extraction of individual CNCs from the fibers. The dimensions of the balsa and kapok CNCs depend on the raw material and oxidation time (Table 1). According to Rashid and Dutta [31], the diameter of CNCs is affected by the width of the cell wall of the raw material. Kapok fibers 
produce CNCs with smaller diameters than balsa fibers. This is probably due to kapok fibers having a smaller cell wall width than balsa fibers. The previous report shows that balsa and kapok fibers have a fiber cell wall width of 2.40 and $1.34 \mu \mathrm{m}$, respectively [1].
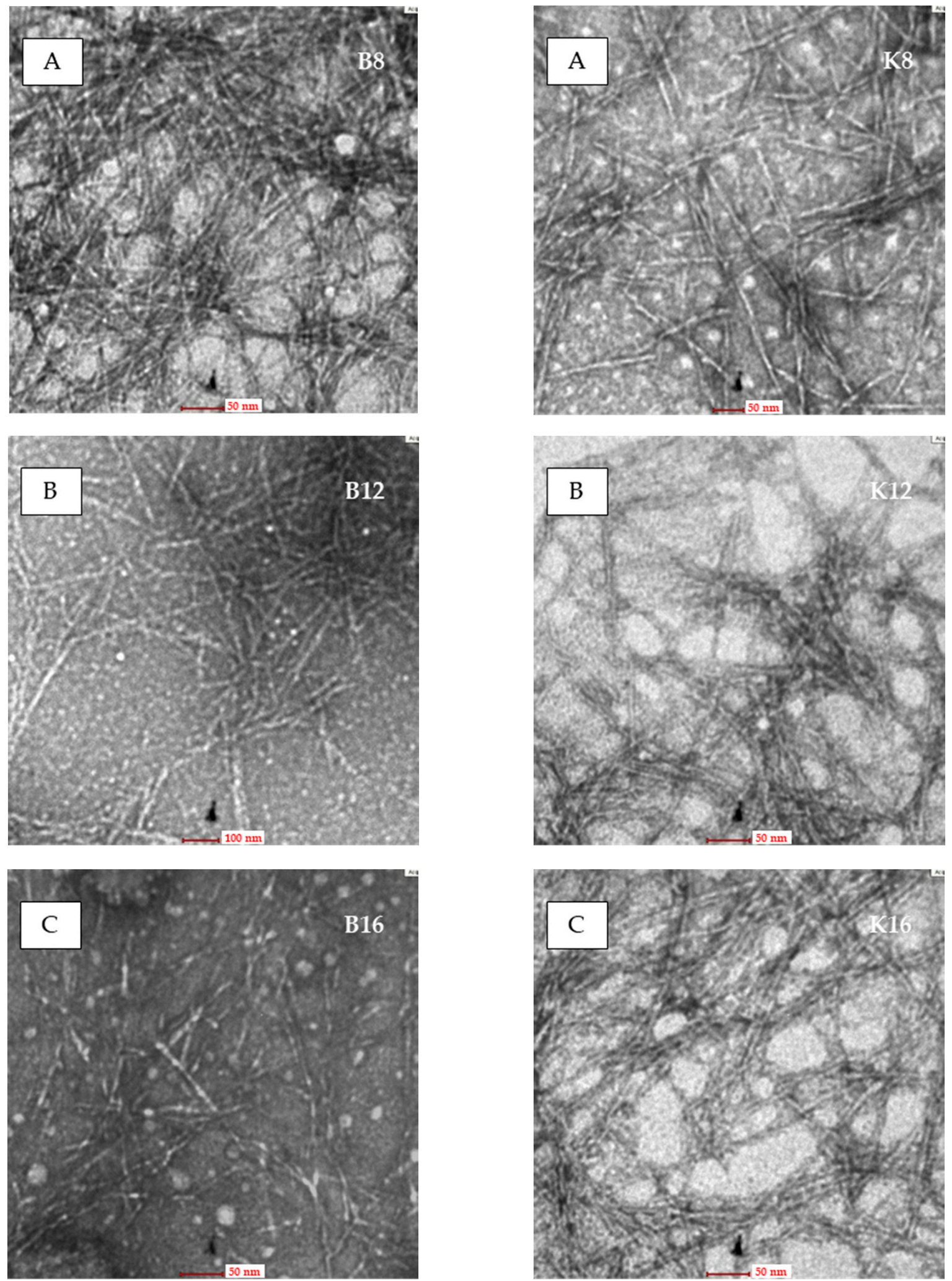

Figure 3. Transmission electron microscopy images of the rod-like CNCs obtained by APS oxidation of balsa fiber (left) and kapok fiber (right) for different oxidation times: (A) $8 \mathrm{~h}$, (B) $12 \mathrm{~h}$, and (C) $16 \mathrm{~h}$. 
Table 1. Balsa and kapok fiber CNC size distributions.

\begin{tabular}{|c|c|c|c|c|c|c|c|c|}
\hline \multirow{2}{*}{ Samples } & \multirow{2}{*}{ Reaction Time (h) } & \multicolumn{3}{|c|}{ Diameter $(\mathrm{D}, \mathrm{nm})$} & \multicolumn{3}{|c|}{ Length $(\mathrm{L}, \mathrm{nm})$} & \multirow{2}{*}{ Aspect Ratio (L/D) } \\
\hline & & Min. & Max. & Ave. * & Min. & Max. & Ave. * & \\
\hline \multirow{3}{*}{ CNCs from Balsa } & 8 & 7.35 & 19.48 & $12.64(\mathrm{a} 0)$ & 115.33 & 482.48 & 274.40 (a2) & 21.72 \\
\hline & 12 & 6.25 & 16.11 & $10.44(\mathrm{~b} 0)$ & 182.57 & 397.60 & $261.58(\mathrm{a} 2)$ & 25.06 \\
\hline & 16 & 3.93 & 11.25 & $6.52(\mathrm{c} 0)$ & 52.60 & 182.65 & 95.88 (b2) & 14.72 \\
\hline \multirow{3}{*}{ CNCs from Kapok } & 8 & 4.62 & 13.86 & 8.77 (a1) & 189.96 & 369.81 & 247.61 (a3) & 28.23 \\
\hline & 12 & 2.78 & 9.16 & 5.54 (b1) & 93.27 & 186.91 & $136.36(\mathrm{~b} 3)$ & 24.61 \\
\hline & 16 & 3.14 & 8.26 & 5.82 (b1) & 82.87 & 152.36 & $112.06(\mathrm{c} 3)$ & 19.24 \\
\hline
\end{tabular}

* Different letters in the same column denote significant differences between treatments according to Duncan's multiple range test with a $5 \%$ confidence interval.

In this study, the nanostructures were produced with a shorter time $(8 \mathrm{~h})$ than the general APS oxidation process $(16 \mathrm{~h})$ [13]. Pretreatment shortens the oxidation time of the APS oxidation method. Pretreatment using sodium chlorite/acetic acid can reduce the fiber impurities and results in a rougher fiber surface [26]. Increasing the surface roughness of fibers increases their porosity in an aqueous medium [32]. This allows APS to penetrate the treated fibers more easily than the untreated fibers. A longer oxidation time increases the imbibition height and capillary mass of the fibers [33]. This accelerates the nanocellulose isolation process.

The average diameter of balsa and kapok CNCs after $8 \mathrm{~h}$ of oxidation time was 12.64 and $8.77 \mathrm{~nm}$, respectively. At the same oxidation time, the average diameter of the kapok CNCs was lower than that of the balsa CNCs. Hence, the diameter of the CNCs prepared using this method was lower than that obtained with the acid hydrolysis method $(16 \mathrm{~nm})$ [34]. The dimensions of both CNCs significantly decreased $(p<0.01)$ with longer oxidation times. A longer oxidation time produced CNCs with a large surface area, which was due to a reduction in the dimensions (length and width) of the CNCs that was caused by the degraded and removed amorphous regions in cellulose during the APS oxidation process [35]. These results are in line with those of previous reports [24,35]. This phenomenon is also supported by the crystallinity index (CI). The CI increased owing to the longer oxidation time. The aspect ratios decreased gradually with the increasing oxidation time and produced a nanoparticle-like form. Nanoparticle-like morphological characteristics occurred after $16 \mathrm{~h}$ of APS oxidation. Both of the CNCs had lengths and diameters smaller than $100 \mathrm{~nm}$.

\subsection{Zeta Potential}

The zeta potential reflects the colloidal stability of CNCs, which is affected by particle dispersion or agglomeration that is caused by electrostatic repulsive forces. The higher absolute value of the $\mathrm{ZP}$ generated a more stable suspension of the $\mathrm{CNCs}$ [35]. A higher $\mathrm{ZP}$ value resulted in a significant repulsive force. In addition, the repulsive forces on the CNCs prevented agglomeration. The $\mathrm{ZP}$ of the CNCs ranged from -10.23 to $-62.27 \mathrm{mV}$, depending on the oxidation time and raw materials (Table 2). The ZP of the CNCs increased with the increasing oxidation time. The highest absolute ZP was achieved after $16 \mathrm{~h}$ of oxidation $(62.27 \mathrm{mV})$ in the kapok CNCs, indicating an increase in the carboxyl group content after the oxidation process with the APS oxidation method. The primary hydroxyl groups on the cellulose surface were converted to carboxyl groups after the APS oxidation method [30]. The ZP value after $16 \mathrm{~h}$ oxidation time in this study was higher than that previously reported with the APS oxidation method and other methods (Table 2). This could be affected by performing the delignification process before the APS oxidation method in the fibers. The higher $\mathrm{ZP}$ value produced strong electrostatic repulsive forces between the CNCs, reduced the light scattering of the CNCs, and hindered their aggregation [31]. Generally, a stable suspension of nanocellulose shows a zeta potential value lower than $-25.0 \mathrm{mV}$ [16]. 
Table 2. Zeta potentials (ZPs) of the CNCs from balsa and kapok fibers.

\begin{tabular}{cccc}
\hline Sample & Reaction Time (h)/Methods & ZP/mV & Literature \\
\hline & 8 & -29.93 & In this study \\
CNCs from balsa & 12 & -44.23 & In this study \\
& 16 & -51.43 & In this study \\
CNCs from kapok & 8 & -10.23 & In this study \\
& 12 & -61.87 & In this study \\
CNCs from cotton & 16 & -62.27 & In this study \\
CNCs from MCC & APS oxidation methods & -50.60 & {$[14]$} \\
CNCs from jute fiber & APS oxidation methods & -46.90 & {$[14]$} \\
CNCs from denim waste & APS oxidation methods & -40.00 & {$[24]$} \\
CNCs from lemon pulp & APS oxidation methods & -3.53 & {$[17]$} \\
CNCs from lemon pulp & APS oxidation methods & -31.27 & {$[16]$} \\
CNCs from lemon pulp & Sulfuric acid (Acid hydrolysis) & -40.27 & {$[16]$} \\
CNCs from cotton pulp & TEMPO Oxidation & -55.67 & {$[16]$} \\
& Phosphoric acid (Acid & -17.03 & {$[36]$} \\
\hline
\end{tabular}

\subsection{Functional Group Analysis}

The untreated balsa and kapok fibers showed differences in the absorption bands measured at 1430-1250,1610, 1750, and $2850 \mathrm{~cm}^{-1}$ due to the different amounts of extractive, hemicellulose, and lignin [37] (Figure 4). The balsa and kapok fibers showed absorbance bands in the spectra at 1595,1508 , and $1230 \mathrm{~cm}^{-1}$, assigned to $\mathrm{C}=\mathrm{O}$ and $\mathrm{C}=\mathrm{C}$ aromatic skeletal vibrations, indicating the presence of lignin and hemicellulose $[38,39]$. These bands were not visible in the CNC spectra after combining the delignification and oxidation processes. This combined process can remove non-cellulosic components in balsa and kapok fibers.
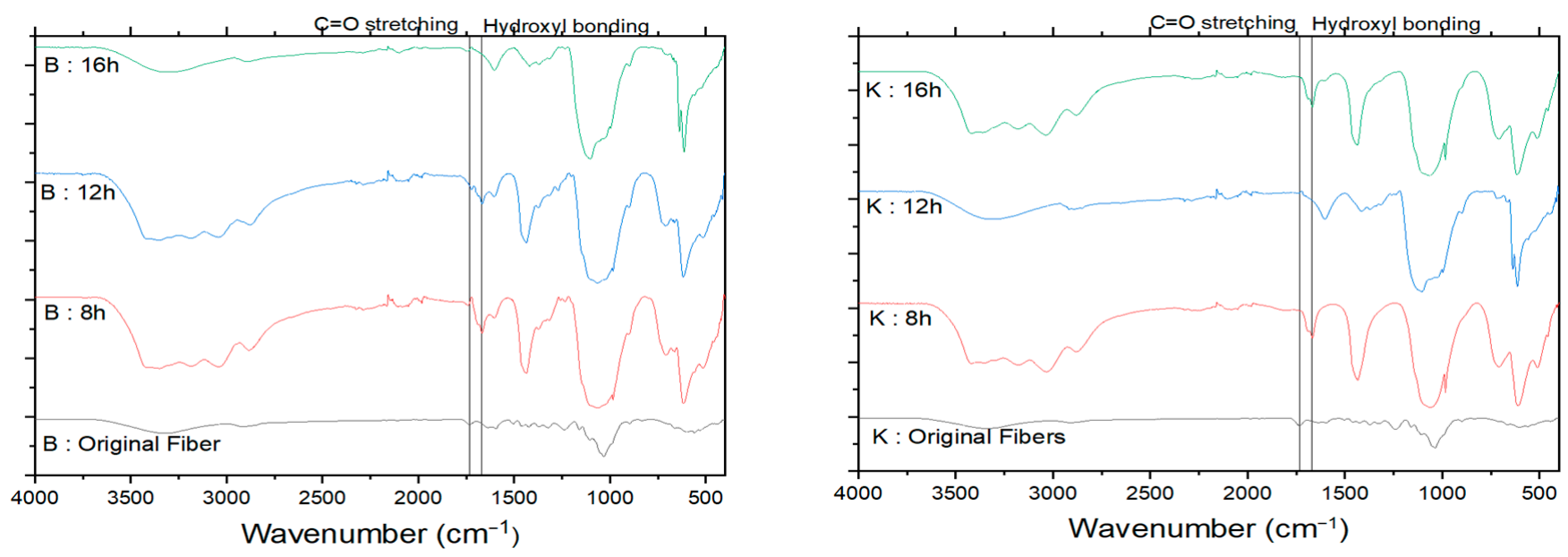

Figure 4. FTIR spectra of balsa (left) and kapok (right) fibers and the resultant CNCs.

The CNCs of balsa and kapok fibers exhibited typical peaks at broad O-H stretching $\left(3600-3100 \mathrm{~cm}^{-1}\right), \mathrm{C}-\mathrm{H}$ stretches $\left(3000-2800 \mathrm{~cm}^{-1}\right), \mathrm{C}-\mathrm{H}$ bends $\left(1450-1300 \mathrm{~cm}^{-1}\right)$, and C-O stretching (1170-1050 $\mathrm{cm}^{-1}$ ) [38]. The CNCs showed more intense cellulose peaks at $\sim 1159,1106$, and $1055 \mathrm{~cm}^{-1}$ [38]. The intense peaks corresponding to the vibrations of cellulose indicates the high purity of the CNCs after the combined process [40]. The balsa and kapok $C N C$ s exhibited a peak of $C=O$ stretching vibration at $1733 \mathrm{~cm}^{-1}$. The carboxylic group is a typical characteristic of CNCs prepared using the APS oxidation method [13]. 


\subsection{Crystallinity Index}

CNCs show a pattern typical of cellulose I (Figure 5). The delignification treatment followed by oxidation did not change this pattern. The CI increased with oxidation time. These results indicate that delignification and APS oxidation did not damage the crystalline region [41]. The same phenomenon was observed in a previous study [35,42]. The cellulose I patterns showed major diffraction peaks at $2 \theta$ of approximately $15.1^{\circ}$ (I $\left.1-10\right), 16.5^{\circ}$ (I 110 ), 20.4 (I 012 ), and 22.6 (I 200 ) [35]. The single crystallinity peaks of the balsa CNCs resulting from 8, 12, and $16 \mathrm{~h}$ of oxidation were $22.09^{\circ}$ (I 200 ), 21.86 (I 200 ), and $21.79^{\circ}$ (I 200 ), respectively. Meanwhile, the crystallinity peaks of the kapok CNCs resulting from 18, 12, and $16 \mathrm{~h}$ of oxidation were $21.93^{\circ}$ (I 20 ), $22.12^{\circ}$ (I 200 ), and $22.41^{\circ}$ (I 20 ), respectively.
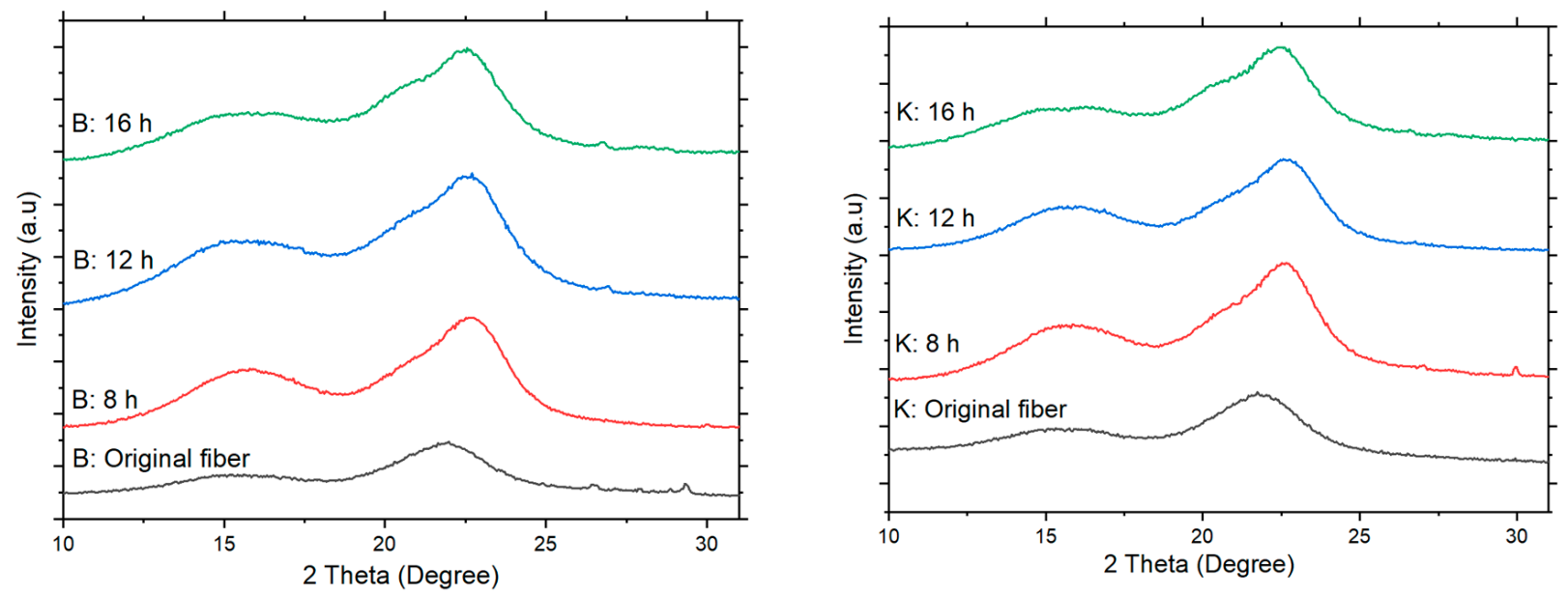

Figure 5. X-ray diffraction (XRD) patterns of the (left) balsa fiber and (right) kapok fiber and the resulting CNCs.

The combined method of delignification and APS oxidation generated a higher CI of CNCs than the raw materials. The CI of the balsa and kapok CNCs increased by 51.24 83.60 and $55.82-70.29 \%$, respectively (Table 3). The increase in the CI of the CNCs was due to the removal of the impurities and amorphous regions of the cellulose during the delignification and APS oxidation processes [27]. These results are consistent with the FTIR analyses. The CI of the balsa CNCs was lower than that of the kapok CNCs. Leung et al. [13] reported that raw materials affect the degree of crystallinity. The longer oxidation time also generated a higher CI of the balsa and kapok CNCs. This is probably because the successive hydrolysis of the amorphous domains results in a higher amount of crystalline domains of the CNCs [35]. The balsa and kapok CNCs in this study have a higher CI compared to the CNCs from the APS oxidation method without delignification at the same concentration [2].

Table 3. Crystallinity indices (CIs) of the balsa and kapok fibers and of the resulting CNCs.

\begin{tabular}{llllc}
\hline \multirow{2}{*}{ Sample } & & \multicolumn{2}{c}{ CI, $^{\circ}$} \\
\cline { 3 - 5 } & & Balsa & Kapok \\
\hline \multirow{2}{*}{ Original fiber } & & 31.40 & 35.65 \\
\multirow{2}{*}{ CNCs } & $8 \mathrm{~h}$ & 47.49 & 55.55 \\
& & $12 \mathrm{~h}$ & 51.00 & 52.50 \\
& & $16 \mathrm{~h}$ & 57.65 & 60.71 \\
\hline
\end{tabular}

\subsection{Thermal Stability}

The thermal stability of the CNCs is lower than that of the original fibers (Figure 6). All of the samples decrease in weight at a low temperature $\left(<60-120^{\circ} \mathrm{C}\right)$, suggesting the 
evaporation of loosely bound moisture [27]. The $T_{\text {onset }}$ decomposition temperatures of the balsa and kapok fibers are 263.80 and $254.49^{\circ} \mathrm{C}$, respectively (Table 4). This is caused by the differences in the chemical composition and morphology of the raw materials. However, the $T_{\text {onset }}$ of the CNCs was below $250{ }^{\circ} \mathrm{C}$. The lower thermal degradation temperature of the CNCs is due to the smaller size of the CNCs. The decreased degradation temperature of the CNCs may be related to their greater surface area compared to the original fibers [43]. Moreover, the decreased degradation temperature may be due to the disruption of hydrogen bonding in the original cellulose upon the addition of the carboxyl group [16].
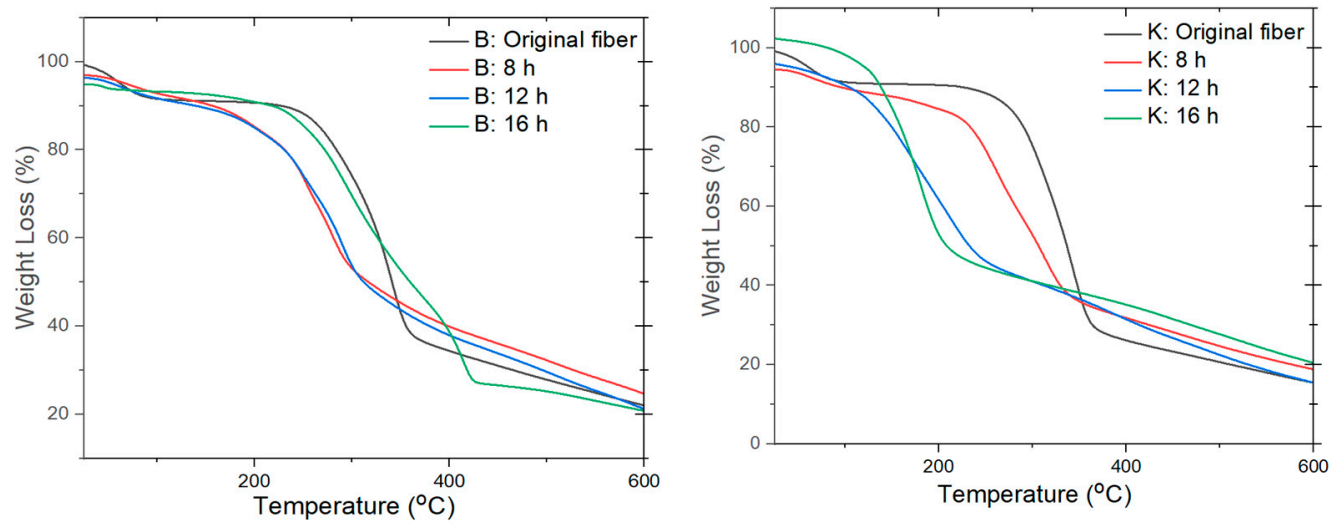

Figure 6. Thermogravimetric analysis (TGA) curves of the balsa fiber (left) and kapok fiber (right) and the resulting CNCs.

Table 4. Decomposition onset temperature and maximum thermal degradation temperature ( $T_{\text {onset }}$ and $T_{\max }$ ) of untreated balsa and kapok fibers and their resulting CNCs.

\begin{tabular}{cccc}
\hline \multirow{2}{*}{ Sample } & Reaction Time (h) & \multicolumn{2}{c}{ Temperature $\left({ }^{\circ} \mathbf{C}\right)$} \\
\cline { 2 - 4 } & & $\boldsymbol{T}_{\text {onset }}$ & $\boldsymbol{T}_{\max }$ \\
\hline \multirow{3}{*}{ Balsa } & Original fiber & 263.80 & 342.64 \\
& 8 & 219.71 & 277.87 \\
& 12 & 240.73 & 289.91 \\
Kapok & 16 & 241.33 & 291.57 \\
& Original fiber & 254.49 & 344.80 \\
& 8 & 215.35 & 261.39 \\
& 12 & 216.97 & 273.93 \\
& 16 & 233.45 & 280.64 \\
\hline
\end{tabular}

The TGA results show that the thermal stability of the kapok fiber CNCs is lower than that of the balsa at the same oxidation time. This is probably due to the smaller size of the CNCs in kapok fibers than in the balsa CNCs. The thermal stability of CNCs is affected by several factors, such as dimensions, specific surface area, and molecular weight [24]. The thermal stability of the balsa and kapok CNCs was also influenced by the oxidation time. The CNCs isolated for $16 \mathrm{~h}$ had a higher thermal stability than the rest. The differences in the thermal decomposition profiles of the CNCs could be affected by varying amounts of surface charge [35] and degree of crystallinity [14]. This is confirmed by the higher zeta potential value and degree of crystallinity with longer oxidation times. The presence of $-\mathrm{COOH}$ groups on the $\mathrm{CNC}$ s surface can increase the thermal stability of the CNCs [5]. The $T_{\text {onset }}$ of the CNCs in this study was higher than that of the CNCs obtained from sulfuric acid hydrolysis $[15,16]$. The higher $T_{\text {onset }}$ of the CNCs derived from the APS oxidation method was due to the presence of carboxyl groups [16].

The two-step isolation of CNCs using the APS oxidation method in balsa and kapok fibers had a higher thermal stability than the CNCs from balsa and kapok reported in a 
previous study [2]. The CNCs from untreated balsa and kapok fibers oxidized by $1 \mathrm{M}$ APS for $16 \mathrm{~h}$ thermally degrade at $191.5-221.8$ and $228.2-264.97^{\circ} \mathrm{C}$, respectively. Conversely, in the present study, the balsa and kapok CNCs fabricated by oxidation with $1 \mathrm{M}$ APS for $8 \mathrm{~h}$ show the following higher values: $219.71-277.87$ and $215.35-261.39^{\circ} \mathrm{C}$, respectively. The combination of the delignification and APS oxidation processes increased the thermal stability of the balsa and kapok CNCs. This indicates that pretreatment could improve the thermal stability of CNCs. The higher thermal stability of CNCs after longer oxidation times may be explained by the higher colloidal stability and higher crystallinity degree.

\section{Conclusions}

The combination of delignification and APS oxidation produced balsa and kapok CNCs with a high zeta potential and a high thermal stability. CNCs have a rod-like structure and gel form. The CNCs of balsa and kapok showed an average diameter of $6.52-12.64$ and $5.82-8.77 \mathrm{~nm}$. Longer oxidation times resulted in smaller diameters and shorter CNCs. In addition, the zeta potential and CI of the balsa and kapok CNCs increased with the increasing oxidation time. Longer oxidation times resulted in the higher thermal stability of the CNCs. These characteristics can expand the use of CNCs in many applications, such as nanofillers, biomedicine, drug delivery, flocculants, and adsorbents.

Author Contributions: Data curation, M.I.M.; methodology, N.J.W., S.-H.L. and S.N.; resources, N.M. and L.H.Z.; supervision, F.F. and N.-H.K.; writing-original draft, M.M. All authors have read and agreed to the published version of the manuscript.

Funding: This research was funded by the PMDSU (grant No. 4123/IT3.L1/PN/2020), WCR (No. 2345/IT3.L1/PN/2021), and the PD (No. 2039/IT3.L1/PN/2021) grant scheme and by the Basic Science Research Program through the National Research Foundation of Korea (NRF), funded by the Ministry of Science and Information and Communication Technology (MSIT) (NRF2019K1A3A9A01000018), and the Basic Science Research Program via the National Research Foundation of Korea (NRF), funded by the Ministry of Education (NRF-2018R1A6A1A03025582).

Institutional Review Board Statement: Not applicable.

Informed Consent Statement: Not applicable.

Data Availability Statement: Not applicable.

Acknowledgments: The authors acknowledge the Deputy of Strengthening for Research and Development, Ministry of Research and Technology/National Research and Innovation Agency of the Republic of Indonesia, for the financial support of this research through the Master's Program of Education Leading to a Doctoral Degree for Excellent Graduates (PMDSU).

Conflicts of Interest: The authors declare no conflict of interest.

\section{References}

1. Purnawati, R.; Febrianto, F.; Wistara, I.N.J.; Nikmatin, S.; Hidayat, W.; Lee, S.H.; Kim, N.H. Physical and chemical properties of kapok (Ceiba pentandra) and balsa (Ochroma pyramidale) fibers. J. Korean Wood Sci. Technol. 2018, 46, 393-401. [CrossRef]

2. Marwanto, M.; Maulana, M.I.; Febrianto, F.; Wistara, N.J.; Nikmatin, S.; Masruchin, N.; Zaini, L.H.; Lee, S.-H.; Kim, N.H. Characteristics of Nanocellulose Crystals from Balsa and Kapok Fibers at Different Ammonium Persulfate Concentration. Wood Sci. Technol. 2021. under review.

3. Xu, X.; Liu, F.; Jiang, L.; Zhu, J.Y.; Haagenson, D.; Wiesenborn, D.P. Cellulose Nanocrystals vs. Cellulose Nanofibrils: A Comparative Study on Their Microstructures and Effects as Polymer Reinforcing Agents. ACS Appl. Mater. Interfaces 2013, 5, 2999-3009. [CrossRef]

4. Jiang, F.; Hsieh, Y.-L. Chemically and mechanically isolated nanocellulose and their self-assembled structures. Carbohydr. Polym. 2013, 95, 32-40. [CrossRef]

5. Mascheroni, E.; Rampazzo, R.; Ortenzi, M.A.; Piva, G.; Bonetti, S.; Piergiovanni, L. Comparison of cellulose nanocrystals obtained by sulfuric acid hydrolysis and ammonium persulfate, to be used as coating on flexible food-packaging materials. Cellulose 2016, 23, 779-793. [CrossRef]

6. Yu, H.-Y.; Zhang, D.-Z.; Lu, F.-F.; Yao, J. New Approach for Single-Step Extraction of Carboxylated Cellulose Nanocrystals for Their Use as Adsorbents and Flocculants. ACS Sustain. Chem. Eng. 2016, 4, 2632-2643. [CrossRef] 
7. Sun, B.; Yu, H.-Y.; Zhou, Y.; Huang, Z.; Yao, J.-M. Single-step extraction of functionalized cellulose nanocrystal and polyvinyl chloride from industrial wallpaper wastes. Ind. Crops Prod. 2016, 89, 66-77. [CrossRef]

8. Niu, F.; Li, M.; Huang, Q.; Zhang, X.; Pan, W.; Yang, J.; Li, J. The characteristic and dispersion stability of nanocellulose produced by mixed acid hydrolysis and ultrasonic assistance. Carbohydr. Polym. 2017, 165, 197-204. [CrossRef] [PubMed]

9. Xie, H.; Zou, Z.; Du, H.; Zhang, X.; Wang, X.; Yang, X.; Wang, H.; Li, G.; Li, L.; Si, C. Preparation of thermally stable and surface-functionalized cellulose nanocrystals via mixed H2SO4/Oxalic acid hydrolysis. Carbohydr. Polym. 2019, $223,115116$. [CrossRef]

10. Liu, W.; Du, H.; Liu, H.; Xie, H.; Xu, T.; Zhao, X.; Liu, Y.; Zhang, X.; Si, C. Highly Efficient and Sustainable Preparation of Carboxylic and Thermostable Cellulose Nanocrystals via FeCl3-Catalyzed Innocuous Citric Acid Hydrolysis. ACS Sustain. Chem. Eng. 2020, 8, 16691-16700. [CrossRef]

11. Bondancia, T.; De Aguiar, J.; Batista, G.; Cruz, A.J.G.; Marconcini, J.M.; Mattoso, L.H.C.; Farinas, C.S. Production of Nanocellulose Using Citric Acid in a Biorefinery Concept: Effect of the Hydrolysis Reaction Time and Techno-Economic Analysis. Ind. Eng. Chem. Res. 2020, 59, 11505-11516. [CrossRef]

12. Wang, H.; Du, H.; Liu, K.; Liu, H.; Xu, T.; Zhang, S.; Chen, X.; Zhang, R.; Li, H.; Xie, H.; et al. Sustainable preparation of bifunctional cellulose nanocrystals via mixed $\mathrm{H}_{2} \mathrm{SO}_{4}$ / formic acid hydrolysis. Carbohydr. Polym. 2021, 266, 118107. [CrossRef] [PubMed]

13. Leung, A.C.W.; Hrapovic, S.; Lam, E.; Liu, Y.; Male, K.B.; Mahmoud, K.; Luong, J.H.T. Characteristics and Properties of Carboxylated Cellulose Nanocrystals Prepared from a Novel One-Step Procedure. Small 2011, 7, 302-305. [CrossRef]

14. Oun, A.A.; Rhim, J.-W. Characterization of carboxymethyl cellulose-based nanocomposite films reinforced with oxidized nanocellulose isolated using ammonium persulfate method. Carbohydr. Polym. 2017, 174, 484-492. [CrossRef] [PubMed]

15. Hu, Y.; Tang, L.; Lu, Q.; Wang, S.; Chen, X.; Huang, B. Preparation of cellulose nanocrystals and carboxylated cellulose nanocrystals from borer powder of bamboo. Cellulose 2014, 21, 1611-1618. [CrossRef]

16. Zhang, H.; Chen, Y.; Wang, S.; Ma, L.; Yu, Y.; Dai, H.; Zhang, Y. Extraction and comparison of cellulose nanocrystals from lemon (Citrus limon) seeds using sulfuric acid hydrolysis and oxidation methods. Carbohydr. Polym. 2020, 238, 116180. [CrossRef]

17. Culsum, N.T.U.; Melinda, C.; Leman, I.; Wibowo, A.; Budhi, Y.W. Isolation and characterization of cellulose nanocrystals (CNCs) from industrial denim waste using ammonium persulfate. Mater. Today Commun. 2021, 26, 101817. [CrossRef]

18. Huang, Z.-X.; Cao, S.-L.; Xu, P.; Wu, H.; Zong, M.-H.; Lou, W.-Y. Preparation of a novel nanobiocatalyst by immobilizing penicillin acylase onto magnetic nanocrystalline cellulose and its use for efficient synthesis of cefaclor. Chem. Eng. J. 2018, 346, 361-368. [CrossRef]

19. Fardioui, M.; Kadmiri, I.M.; Qaiss, A.E.K.; Bouhfid, R. Bio-active nanocomposite films based on nanocrystalline cellulose reinforced styrylquinoxalin-grafted-chitosan: Antibacterial and mechanical properties. Int. J. Biol. Macromol. 2018, 114, 733-740. [CrossRef]

20. Karimian, A.; Parsian, H.; Majidinia, M.; Rahimi, M.; Mir, S.M.; Kafil, H.S.; Shafiei-Irannejad, V.; Kheyrollah, M.; Ostadi, H.; Yousefi, B. Nanocrystalline cellulose: Preparation, physicochemical properties, and applications in drug delivery systems. Int. J. Biol. Macromol. 2019, 133, 850-859. [CrossRef]

21. Adel, A.; El-Shafei, A.; Ibrahim, A.; Al-Shemy, M. Extraction of oxidized nanocellulose from date palm (Phoenix dactylifera L.) sheath fibers: Influence of CI and CII polymorphs on the properties of chitosan/bionanocomposite films. Ind. Crops Prod. 2018, 124, 155-165. [CrossRef]

22. Du, H.; Liu, W.; Zhang, M.; Si, C.; Zhang, X.; Li, B. Cellulose nanocrystals and cellulose nanofibrils based hydrogels for biomedical applications. Carbohydr. Polym. 2019, 209, 130-144. [CrossRef] [PubMed]

23. Liu, W.; Du, H.; Zhang, M.; Liu, K.; Liu, H.; Xie, H.; Zhang, X.; Si, C. Bacterial Cellulose-Based Composite Scaffolds for Biomedical Applications: A Review. ACS Sustain. Chem. Eng. 2020, 8, 7536-7562. [CrossRef]

24. Bashar, M.M.; Zhu, H.; Yamamoto, S.; Mitsuishi, M. Highly carboxylated and crystalline cellulose nanocrystals from jute fiber by facile ammonium persulfate oxidation. Cellulose 2019, 26, 3671-3684. [CrossRef]

25. Jang, J.-H.; Hayashi, N.; Han, S.-Y.; Park, C.-W.; Febrianto, F.; Lee, S.-H.; Kim, N.-H. Changes in the Dimensions of Lignocellulose Nanofibrils with Different Lignin Contents by Enzymatic Hydrolysis. Polymers 2020, 12, 2201. [CrossRef]

26. Jin, K.; Liu, X.; Jiang, Z.; Tian, G.; Yang, S.; Shang, L.; Ma, J. Delignification kinetics and selectivity in poplar cell wall with acidified sodium chlorite. Ind. Crops Prod. 2019, 136, 87-92. [CrossRef]

27. Oun, A.A.; Rhim, J.-W. Isolation of oxidized nanocellulose from rice straw using the ammonium persulfate method. Cellulose 2018, 25, 2143-2149. [CrossRef]

28. Segal, L.; Creely, J.; Martin, A.; Conrad, C. An Empirical Method for Estimating the Degree of Crystallinity of Native Cellulose Using the X-ray Diffractometer. Text. Res. J. 1959, 29, 786-794. [CrossRef]

29. Mendoza, L.; Gunawardhana, T.; Batchelor, W.; Garnier, G. Effects of fibre dimension and charge density on nanocellulose gels. J. Colloid Interface Sci. 2018, 525, 119-125. [CrossRef]

30. Mendoza, D.J.; Hossain, L.; Browne, C.; Raghuwanshi, V.S.; Simon, G.P.; Garnier, G. Controlling the transparency and rheology of nanocellulose gels with the extent of carboxylation. Carbohydr. Polym. 2020, 245, 116566. [CrossRef]

31. Rashid, S.; Dutta, H. Characterization of nanocellulose extracted from short, medium and long grain rice husks. Ind. Crops Prod. 2020, 154, 112627. [CrossRef] 
32. Xiao, B.; Zhang, Y.; Wang, Y.; Jiang, G.; Liang, M.; Chen, X.; Long, G. A fractal model for kozeny-carman constant and dimensionless permeability of fibrous porous media with roughened surfaces. Fractals 2019, 27, 1-12. [CrossRef]

33. Xiao, B.; Huang, Q.; Chen, H.; Chen, X.; Long, G. A fractal model for capillary flow through a single tortuous capillary with roughened surfaces in fibrous porous media. Fractals 2021, 29, 2150017. [CrossRef]

34. Deepa, B.; Abraham, E.; Cordeiro, N.; Mozetic, M.; Mathew, A.P.; Oksman, K.; Faria, M.; Thomas, S.; Pothan, L.A. Utilization of various lignocellulosic biomass for the production of nanocellulose: A comparative study. Cellulose 2015, 22, 1075-1090. [CrossRef]

35. Khanjanzadeh, H.; Park, B.-D. Optimum oxidation for direct and efficient extraction of carboxylated cellulose nanocrystals from recycled MDF fibers by ammonium persulfate. Carbohydr. Polym. 2021, 251, 117029. [CrossRef]

36. Vanderfleet, O.M.; Osorio, D.A.; Cranston, E.D. Optimization of cellulose nanocrystal length and surface charge density through phosphoric acid hydrolysis. Philos. Trans. R. Soc. A Math. Phys. Eng. Sci. 2018, 376, 20170041. [CrossRef] [PubMed]

37. Jordan, J.H.; Easson, M.W.; Dien, B.; Thompson, S.; Condon, B.D. Extraction and characterization of nanocellulose crystals from cotton gin motes and cotton gin waste. Cellulose 2019, 26, 5959-5979. [CrossRef]

38. KKhanjanzadeh, B.D. Park, Characterization of carboxylated cellulose nanocrystals from recycled fiberboard fibers using ammonium persulfate oxidation. J. Korean Wood Sci. Technol. 2020, 48, 231-244. [CrossRef]

39. Goh, K.Y.; Ching, Y.C.; Chuah, C.H.; Abdullah, L.C.; Liou, N.-S. Individualization of microfibrillated celluloses from oil palm empty fruit bunch: Comparative studies between acid hydrolysis and ammonium persulfate oxidation. Cellulose 2016, 23, 379-390. [CrossRef]

40. Zhao, G.; Du, J.; Chen, W.; Pan, M.; Chen, D. Preparation and thermostability of cellulose nanocrystals and nanofibrils from two sources of biomass: Rice straw and poplar wood. Cellulose 2019, 26, 8625-8643. [CrossRef]

41. Filipova, I.; Fridrihsone, V.; Cabulis, U.; Berzins, A. Synthesis of Nanofibrillated Cellulose by Combined Ammonium Persulphate Treatment with Ultrasound and Mechanical Processing. Nanomaterials 2018, 8, 640. [CrossRef] [PubMed]

42. Zaini, L.H.; Febrianto, F.; Wistara, I.N.J.; Marwanto, N.; Maulana, M.I.; Lee, S.H.; Kim, N.H. Effect of ammonium persulfate concentration on characteristics of cellulose nanocrystals from oil palm frond. J. Korean Wood Sci. Technol. 2019, 47, 597-606. [CrossRef]

43. Zhang, K.; Sun, P.; Liu, H.; Shang, S.; Song, J.; Wang, D. Extraction and comparison of carboxylated cellulose nanocrystals from bleached sugarcane bagasse pulp using two different oxidation methods. Carbohydr. Polym. 2016, 138, 237-243. [CrossRef] [PubMed] 